\title{
ESTRATÉGIAS PARA o DESENVOLVIMENTO Sustentável e Programas de Educação ExeCutiva: UMA CONTRIBUIÇÃO DO PENSAMENTO CONECTIVO
}

\section{RESUMO}

Este artigo apresenta um ensaio teórico que tem como objetivo identificar práticas pedagógicas e estruturas curriculares para o desenvolvimento do pensamento conectivo em Programas de Educação Executiva. Considerase, nesta perspectiva, que o pensamento conectivo - capaz de captar inter-relações, implicações mútuas, fenômenos multidimensionais - é essencial para que a consciência dos executivos sobre a relevância do desenvolvimento sustentável para a sociedade, para o meio ambiente, para as organizações e para os indivíduos oriente os seus processos decisórios. Com base em uma extensa revisão bibliográfica de estudos anteriores sobre o tema, foram analisados com maior profundidade práticas pedagógicas e estruturas curriculares que contribuem para o desenvolvimento do pensamento conectivo. Conclui-se que os micromundos e estudos de caso constituem práticas pedagógicas efetivas para o desenvolvimento do pensamento conectivo e que a configuração interdisciplinar é essencial para a definição das estruturas curriculares e dos conteúdos das disciplinas.

Palavras-chave: Pensamento conectivo, Desenvolvimento sustentável, Práticas pedagógicas
Karina De Déa Roglio

Doutora em Engenharia de Produção

Professora do Programa de Pós-graduação em Administração da PUCPR karina.roglio@pucpr.br

Jansen Maia Del Corso Doutor em Doctorado en Management Science. Professora do Programa de Pós-graduação em Administração da PUCPR del.corso@pucpr.br

Wesley Vieira da Silva

Doutor em Engenharia de Produção Professor do Programa de Pós-graduação em Administração da PUCPR wesley.vieira@pucpr.br
This artide aims at identifying teaching practices and curriaular structures for the development of connective thinking in Educational Programs for Executives. Within this perspective, it is considered that connective think ing, which is capable of apprehending interrelationships, mutual implications, and multidimensional phenomena, is essential to make ex ecutives aware of the relevance of sustainable development for society as a whole, for the environment, as well as for individuals and organizations in their decision making processes. Based on an extensive bibliographic review on this subject, only pedagogical practices and arricular structures which contribute to the development of connective think ing have been more deeply analyzed. One may conclude that micro-worlds and case studies make up effective pedagogical practices, and that interdisaiplinary configuration is essential for the definition of arrialar struatures and contents.

Key words: Connective thinking, Sustainable development, Pedagogical practices. 


\section{INTRODUÇÃO}

A complexidade da realidade atual pode ser percebida em muitos aspectos da vida humana: nas interconexões entre as pessoas, as organizações e as sociedades, na multiplicidade de fatores envolvidos em processos decisórios, nas relações homem-natureza, nas transformações organizacionais. Morin (2002, p. 38) apresenta a seguinte definição de complexidade:

Complexus significa o que foi tecido junto; de fato, há complexidade quando elementos diferentes são inseparáveis constitutivos do todo (como o econômico, o político, o sociológico, o psicológico, o afetivo, o mitológico), e há um tecido interdependente, interativo e inter-retroativo entre o objeto de conhecimento e seu contexto, as partes e o todo, o todo e as partes, as partes entre si.

Essa complexidade exige que o ser humano desenvolva uma nova forma de olhar para o mundo. $\mathrm{Na}$ percepção de Wheatley (1999, p. 52), é necessário enxergá-lo não mais como um objeto inanimado, mas como "uma complexa e infinita tapeçaria em permanente mudança".

A importância e a urgência de se explorar e compreender a noção de complexidade são reforçadas na medida em que os problemas com os quais a sociedade se defronta caracterizamse, cada vez mais, pela multidimensionalidade e pela incerteza inerentes aos sistemas complexos. Essa compreensão começa pela substituição da visão do mundo enquanto máquina para uma visão deste enquanto um sistema vivo, formado por conjuntos de subsistemas em interação constante entre si e com o ambiente externo.

Os processos de interação entre os componentes de um sistema, que se caracterizam pela alternância entre a ordem e a desordem, são analisados por diversos autores - Axelrod e Cohen (2000), Hock (1999), Morgan (2000), Senge (1990) e Stacey (1996). Entre eles, existe o pensamento comum de que o caminho da evolução de um sistema é imprevisível em função da sua complexidade e não-linearidade, que fazem com que alterações aparentemente insignificantes possam ter desdobramentos de grandes efeitos.

No momento, a maneira mais sofisticada de reconhecer a complexidade do mundo consiste, segundo Wheatley (1999), em construir elaborados mapas de sistemas e de processos, com freqüência influenciados por uma busca pela constância e previsibilidade. Entretanto, esses mapas retratam apenas uma realidade estática que, na prática, se encontra em um estado contínuo de transformação. Para essa autora, "o desafio consiste em ver, para além dos inúmeros fragmentos, a totalidade, recuando o bastante para apreciar o modo como as coisas se movimentam e se alteram enquanto unidade coerente" (WHEATLEY, 1999, p. 54).

A esse respeito, Senge (2003, p. 7) afirma que para criar um futuro que as pessoas desejam para a sociedade global e que as deixe orgulhosas diante das gerações futuras, "é necessário corrigir os desequilíbrios dessa sociedade, seja a distribuição de renda, o desenvolvimento da sociedade civil ou a destruição dos sistemas vivos. Para isso, precisa-se enxergar as conexões que permeiam os sistemas naturais e sociais". Entretanto, a dinâmica das sociedades modernas obscurece essas conexões, inibindo não somente a ação, mas a própria capacidade de pensar de forma sistêmica.

A definição de desenvolvimento sustentável, publicada pela Comissão de Meio Ambiente e Desenvolvimento da Organização das Nações Unidas em 1987, é: "atender as necessidades da geração presente sem comprometer a habilidade das gerações futuras de atender suas próprias necessidades". De acordo com Senge et al. (2006), essa definição introduziu um novo objetivo para o desenvolvimento econômico que, para ser alcançado, requer que as pessoas, as organizações e as sociedades sejam capazes de compreender a dinâmica dos sistemas complexos em sua totalidade, inserindo-a como um elemento determinante nos processos decisórios.

Nas palavras de Morin (2002, p. 192), "a complexidade é uma maneira de ver o mundo, de pensá-lo, de se repensar a si próprio". Esse autor considera que o maior desafio do pensamento contemporâneo é pensar a complexidade, o que requer uma reforma do modo de pensar. Este trabalho analisa as possibilidades para que os programas de educação executiva se tornem agentes dessa reforma no modo de pensar, de forma que os executivos enxerguem as conexões que permeiam os sistemas naturais e sociais e, conseqüentemente, se conscientizem da relevância de definir e implementar estratégias que promovam o desenvolvimento sustentável da sociedade.

Considera-se, nesta perspectiva, que o pensamento conectivo - capaz de captar inter-relações, implicações mútuas, fenômenos multidimensionais, ou seja, a relação recíproca entre todas as partes de um sistema - é essencial para que a consciência dos executivos sobre a relevância do desenvolvimento sustentável para a sociedade, o meio ambiente, as organizações e os indivíduos oriente os seus processos decisórios.

\section{METODOLOGIA}

Por se tratar de um ensaio teórico, a presente pesquisa baseou-se em uma extensa revisão da literatura publicada no Brasil e no exterior sobre os temas investigados. Optou-se pelo resgate de autores que analisam esses temas sob uma perspectiva crítica e que discutem possibilidades para o aperfeiçoamento dos Programas de Educação Executiva, em particular a relevância dos executivos incorporarem a busca pelo desenvolvimento sustentável em seus processos decisórios.

Sem a pretensão de esgotar as idéias anteriormente investigadas e publicadas, realizou-se o levantamento, a análise e reflexão sobre os seguintes temas: (1) a educação no século XXI, baseada em uma comparação entre instituições educacionais com características predominantemente mecanicistas e instituições que se caracterizam como organizações em aprendizagem; (2) críticas à efetividade dos Programas de Educação Executiva para desenvolver profissionais com o perfil requerido pela realidade atual; (3) o conceito de pensamento conectivo, considerado como um propulsor para estimular a consciência dos executivos sobre a relevância e a urgência de estabelecer estratégias que contemplem o desenvolvimento sustentável; (4) práticas pedagógicas e con- 
teúdos curriculares de Programas de Educação Executiva, com o propósito de identificar a sua relevância para o desenvolvimento do pensamento conectivo nesses programas.

\section{A EDUCAÇÃO NO SÉCULO XXI}

A educação constitui uma força motriz dos movimentos sociais, organizacionais e individuais em busca de novos referenciais. De acordo com a Comissão Internacional sobre Educação para o século XXI da UNESCO,

um dos principais papéis reservados à educação consiste, antes de mais nada, em dotar a humanidade da capacidade de dominar o seu próprio desenvolvimento. Ela deve, de fato, fazer com que cada um tome o seu destino nas mãos e contribua para o progresso da sociedade em que vive, baseando o desenvolvimento na participação responsável dos indivíduos e das comunidades (DELORS, 2000, p. 82).

A análise dos processos educacionais vigentes, à luz dessa afirmação, desperta dúvida sobre o cumprimento efetivo desse papel. Alicerçados sobre os fundamentos positivistas do século $\mathrm{XIX}$, a maioria dos processos educacionais acontece em escolas mecanicistas dissociadas do mundo real. Isoladas em suas fronteiras, essas escolas não preparam seus estudantes para compreender a complexidade do ambiente fora dos muros escolares e para agir neste ambiente de forma a ampliar os horizontes da sociedade em que atuarão (SENGE et al., 2000).

Em geral, as críticas sobre os processos educacionais apontam o fato de estes estarem fundamentados sobre uma visão reducionista e em descompasso com o ritmo das mudanças contemporâneas. Por isso, o legado da visão da ciência clássica positivista na educação está sendo discutido por diversos autores, dentre os quais destacam-se: Demo (2002), Fullan e Hargreaves (2000), Light e Cox (2001), Morin (2002), Morin e Le Moigne (2000), Österman e Kottkamp (2004), Schön (1983, 1987), Senge et al. (2000), que chamam a atenção para a sua inadequação às demandas atuais da sociedade.

Morin (2002) observa que os desenvolvimentos do século $\mathrm{XX}$ fizeram com que a humanidade se defrontasse, cada vez mais amiúde e de modo inevitável, com os desafios da complexidade. Até então, a negação da complexidade pela ciência clássica fundamentou-se nos princípios da ordem, da separação, da redução e do caráter absoluto da lógica dedutivo-identitária. Agora, a complexidade torna a reforma do pensamento uma questão central da educação, pois o parcelamento e a divisão dos saberes impedem as pessoas de aprender o que está tecido junto, o complexo.

Light e Cox (2001), ao analisarem a educação superior, comparam o atual movimento de transição na educação a uma tempestade: as condições de incerteza e ambigüidade que permeiam a educação superior produzem a sensação de estar no meio de uma tempestade. Assim como outras tempestades, provocadas por mudanças nos sistemas estabelecidos, a tempestade acadêmica é conseqüência de mudanças nas relações entre a educação superior, o conhecimento e a sociedade. O problema, complementam os autores, é que não existe nenhum arcabouço sólido de conceitos para dar um sentido a essas mu- danças, compreendê-las e identificar caminhos para enfrentá-las na medida em que elas tomam forma. Na educação superior, particularmente, vive-se no período da supercomplexidade, no qual os arcabouços utilizados para compreender o mundo estão sendo questionados.

A compreensão dessas mudanças começa com a identificação das influências do positivismo sobre o pensamento humano em geral e sobre os processos educacionais em particular. O pensamento positivista teve uma influência social ampla e desencadeou um processo de mecanização da vida humana como um todo. De acordo com Morgan (2000, p. 35),

o uso das máquinas transformou radicalmente a
natureza da atividade produtiva e deixou sua marca na
imaginação, nos pensamentos e nos sentimentos
humanos ao longo do tempo [...] Fomos aprendendo
cada vez mais a usar a máquina como uma metáfora
para nós mesmos e para a nossa sociedade e a moldar o
nosso mundo de acordo com os princípios mecanicistas.

Esse processo teve forte influência sobre as organizações do século XIX, inclusive sobre as instituições de ensino. Os seus reflexos são percebidos não apenas nas estruturas educacionais burocráticas, mas também nos processos de ensino-aprendizagem e nos conteúdos curriculares. Light e Cox (2001), Schön (1983) e Senge et al. (2000) observam que as instituições de ensino podem ser consideradas como o mais completo exemplo de uma instituição mecanicista. As principais características dessas instituições, analisadas por esses autores, são listadas no Quadro 1.

É possível identificar um movimento em direção à redefinição desse modelo em todos os níveis do sistema educacional. De acordo com Morin e Le Moigne (2000), a postura reducionista provocou a concentração do sistema educativo na objetividade científica e rompeu com a missão tradicional da filosofia de pensar e refletir sobre os saberes adquiridos pelas ciências. Por isso, a transformação dos processos educacionais precisa restabelecer a conexão entre a ciência e a filosofia. De outra forma, torna-se extremamente difícil compreender a realidade complexa e estabelecer parâmetros para um desenvolvimento sustentável.

$\mathrm{Na}$ tentativa de delinear os contornos de uma instituição de aprendizagem construída com base em uma nova proposta educacional, que supera o referencial mecanicista e contempla as demandas da sociedade complexa, Light e Cox (2001), Schön (1983), Senge et al. (2000) e Southworth (2000) relacionam algumas características que são listadas no Quadro 2.

Light e Cox (2001) observam que existem sinais claros do esgotamento dos processos educacionais concebidos de acordo com os parâmetros positivistas, que se acentuam na medida em que as condições históricas sobre as quais estes foram construídos estão sofrendo profundas transformações. Mas, a transição do pensamento simplificador para o pensamento complexo é uma verdadeira revolução e requer determinação e ousadia para trilhar novos caminhos. Esses autores afirmam que:

o ritmo atual da mudança social e tecnológica está impulsionando os professores a pensar em termos de educar os estudantes não para os problemas de hoje, 
mas para aqueles de amanhã. Nós demandamos grande flexibilidade e imaginação para educar para o futuro e queremos que os nossos estudantes desenvolvam a capacidade de aprender e a habilidade para transferir o que é aprendido para situações novas e mais complexas (LIGHT; COX, 2001, p. 69).

\section{INSTITUIÇÕES MECANICISTAS}

- Sistema objetivo de normas e procedimentos formais, administrados por meio de uma estrutura hierárquica;

o Funcionamento em uma velocidade uniforme, com sinos e tempos diários rigidamente estabelecidos. Os dias da semana, dos meses e do ano escolar são proporcionalmente divididos, de acordo com os conteúdos definidos na grade curricular;

- Ênfase nos instrumentos de avaliação de natureza quantitativa, que permite ao sistema de controle exibir uma aparência de consistência, uniformidade, precisão e imparcialidade;

- Os professores são especialistas técnicos, cada qual responsável por uma área específica do conhecimento;

- Cada professor sabe os conteúdos que devem ser abordados para manter a linha em movimento, embora tenha pouca influência sobre a velocidade em que a linha deve mover-se, que é pré-determinada pelos dirigentes escolares e pelos currículos padronizados;

- Os estudantes são divididos de acordo com a idade e pressupõe-se que todos se moverão juntos ao longo dos diferentes estágios, isto é, assume-se que todos os estudantes aprendem da mesma forma e na mesma velocidade;

- Cada estágio possui supervisores locais - os professores responsáveis pelas disciplinas, que controlam com instrumentos objetivos, como testes e exames, os resultados do processo de ensino. Os professores, por sua vez, também são constantemente monitorados e recompensados ou punidos, de acordo com os resultados do seu desempenho;

- Os estudantes são considerados produtos da aprendizagem, ao invés de seus criadores.

Quatro 1: Características das instituições de educação mecanicistas

Fonte: elaboração com base em Light e Cox (2001); Schön (1983); Senge et al. (2000).

Essa perspectiva traz diferentes desafios para aqueles envolvidos com processos educacionais. Criar instituições de aprendizagem não constitui tarefa fácil, pois representa uma reconceituação de padrões profundamente arraigados na sociedade. Qualquer estratégia de mudança deve contemplar os diversos fatores que influenciam o sistema educacional, as interações entre as suas partes e as interdependências internas e externas, que for- mam um sistema complexo de relações. Deste modo, a introdução do pensamento complexo e transdisciplinar - ou pensamento conectivo - na educação é fundamental para que as instituições possam cumprir sua missão no atual ambiente de complexidade: estimular os estudantes a criticar, articular, refletir, religar, contextualizar, globalizar, reunir e aplicar o conhecimento.

\section{INSTITUIÇÕES DE APRENDIZAGEM}

- Estrutura flexível, na qual ocorre a constante exploração das teorias-em-uso por parte de todos os envolvidos no processo educacional. $\mathrm{O}$ conhecimento é construído socialmente;

- O professor possui liberdade para refletir, inventar e diferenciar, e assim transpor a ordem institucional de tempo e espaço;

- O currículo se transforma em um inventário de temas a serem abordados, ao invés de conteúdos fixos a serem estudados;

- O professor pensa e age não mais como um especialista técnico, restrito à sua área de conhecimento, mas como um profissional reflexivo;

- Encorajamento da diversidade, não da homogeneidade: predomina a aceitação das múltiplas inteligências e dos diferentes estilos de aprendizagem;

- Compreensão do mundo de interdependência e de mudança, ao invés da memorização de fatos e da busca por respostas corretas;

- A supervisão e as avaliações adquirem um novo significado: os instrumentos qualitativos de avaliação e as narrativas sobre experiências e resultados do ensino e da aprendizagem se tornam os principais referenciais para o acompanhamento dos resultados;

- A aprendizagem é centrada no aprendiz e não no professor;

- Reintegração da educação dentro das redes de relações sociais, conectando-a aos amigos, famílias e comunidades.

Quatro 2: Características das novas instituições de aprendizagem

Fonte: elaboração com base em Light e Cox (2001); Senge et al. (2000); Southworth (2000).

\section{PROGRAMAS DE EDUCAÇÃO EXECUTIVA}

As transformações discutidas na subseção anterior estão sendo analisadas nos diversos níveis do sistema educacional e áreas do conhecimento. Neste trabalho, as discussões giram em torno das práticas pedagógicas e dos conteúdos curriculares dos programas de educação executiva. O propósito é identificar de que forma esses programas podem contribuir para que a consciência sobre a relevância do desenvolvimento sustentável seja incorporada aos processos decisórios dos executivos. 
Algumas inconsistências decorrentes das lacunas entre ação e reflexão no desempenho das funções executivas - reveladas pelas pesquisas de Argyris (1982), Gosling e Mintzberg (2003), Jackall (1988), Mintzberg (1989) e Senge (1990) - estão relacionadas a deficiências nos processos de desenvolvimento desses profissionais. De acordo com Schön (1983), o problema está na lacuna existente entre as duas visões predominantes sobre $o$ conhecimento profissional na área da administração: a visão do gestor como um técnico e a visão deste como um educador.

A principal conseqüência da supremacia da primeira é que a maioria das teorias da administração tem um elemento de verdade, característico da concepção tradicional da ciência, que desconsidera a complexidade das realidades às quais as teorias devem ser aplicadas. É preciso reconhecer que a arte da administração inclui algo como a ciência em ação. Mais do que isso, Schön (1983) afirma que é preciso romper com a idéia ortodoxa de uma única ciência e reestabelecer as conexões entre ciência e arte, criando uma relação de complementaridade entre a ciência e a arte da administração.

Uma ciência da administração mais abrangente, útil e reflexiva poderia ser construída com base na ampliação e aperfeiçoamento sobre o que os gestores efetivos realmente fazem. Os profissionais poderiam, então, tornar-se não apenas os usuários, mas os designers da ciência administrativa (SCHÖN, 1983, p. 266).

Drucker e Senge (2000) concordam que existe um elemento completamente negligenciado nos programas formais de educação gerencial: o inesperado. De acordo com esses autores, pretende-se que os estudantes calculem as situações, façam a máquina funcionar e corrijam os problemas na medida em que estes aparecem. Mas, na verdade, ao criar algo, os fatores mais importantes são aqueles que não foram previstos. De fato, prosseguem esses autores, existe uma diferença entre a orientação para a criação e a orientação para a solução de problemas e a maioria das organizações é dominada pela segunda. A principal razão é que as escolas de administração enfatizam as técnicas de solução de problemas porque é mais fácil ensinar respostas certas e respostas erradas, enquanto ensinar o pensamento reflexivo representa, ainda, um desafio para muitos professores.

Bennis e O 'Toole (2005, p. 98) afirmam que a causa da atual crise na educação em administração está relacionada com 0 dilema entre o rigor e a relevância. Esses autores criticam o modelo da excelência acadêmica, adotado nas melhores escolas de MBA, que consideram o rigor da pesquisa científica como principal fator de avaliação da sua performance.

elas adotaram um modelo de ciência que utiliza análises financeiras e econômicas abstratas, regressões estatísticas e laboratórios de psicologia. Algumas pesquisas produzidas são excelentes, mas em função de poucas delas serem fundamentadas em práticas administrativas reais, o foco dos programas de pós-graduação em Administração tem se tornado cada vez mais circunscrito - e menos relevante para os profissionais.

O problema prossegue os autores supracitados, não é o fato de essas escolas terem adotado o rigor científico, mas o fato de que renunciaram a outras formas de conhecimento. Em sua opinião, é necessário que as escolas de administração busquem o equilíbrio entre o rigor científico e a relevância prática. Ghoshal (2005, p. 77) concorda com esses autores ao afirmar que "nós adotamos a abordagem 'científica' na tentativa de descobrir padrões e leis e substituímos todas as noções de intencionalidade humana com a firme crença no determinismo causal para explicar todos os aspectos da performance corporativa".

Em busca de respostas para essas críticas, Davel et al. (2004), Gosling e Mintzberg (2003), G. Smith (2003), Grey (2004), Kolb (1984), Smith (2001), Reynolds e Vince (2004), Roglio (2006) e Schön (1987), dentre outros autores, investigam diferentes possibilidades para a reestruturação de programas educacionais na área de administração. A partir dos estudos desses autores, a principal idéia desenvolvida nos itens subseqüentes é que o desenvolvimento do pensamento conectivo nos programas de educação executiva é um estímulo para que os executivos incorporem questões fundamentais para o desenvolvimento sustentável na definição das estratégias organizacionais.

\subsection{O conceito de pensamento conectivo}

A necessidade de novas formas de pensamento para trazer o desenvolvimento sustentável do plano das idéias para o plano da ação é mencionada por Ehrenfeld (2004), Morin e Le Moigne (2000), Morin (2002), Schön (1983), Senge (2003), Senge et al. (2006), Weathley (1999). Ehrenfeld (2004, p. 2) afirma que:

precisamos mudar do modo reducionista de resolver problemas para um modo orientado por uma visão de desenvolvimento sustentável compartilhada por todos. Nós precisamos refletir cuidadosamente sobre o estado atual dos negócios e substituir formas inefetivas de pensar e de agir.

O conceito de pensamento conectivo utilizado neste trabalho é apresentado por Roglio (2006). Segundo a autora, a palavra conectivo está relacionada à noção de união, ligação, que traduz a idéia central dessa forma de pensar: a compreensão das conexões entre os diferentes elementos que interagem em um sistema e a associação entre idéias e fatos para gerar soluções criativas.

Senge et al. (2004, p. 194) afirmam que conectividade é a característica que define uma nova visão de mundo: "conectividade como um princípio organizador do universo, conectividade entre o "mundo externo" dos fenômenos manifestos e o "mundo interno" da experiência vivida e, enfim, conectividade entre os seres humanos e o mundo".

De acordo com Smyre (2004, p. 71), por meio do pensamento conectivo as pessoas conectam novas idéias, conceitos, métodos, processos e técnicas emergentes em uma abordagem de constante mudança.

Quando nos tornamos mais e mais parte de um mundo altamente tecnológico e interconectado, a nossa sobrevivência dependerá de como nós transformamos nossas suposições de um mundo baseado na importância percebida da independência para um mundo focado na sustentabilidade da interdependência. 
Ao adotar uma orientação interdependente, observa Roberts (1997), as pessoas compreendem que fazem parte de um todo maior que é fruto das suas próprias decisões e ações. Essa autora afirma que executivos que assumem essa orientação consideram, na definição das estratégias organizacionais, questões como "a quem impactarão nossas ações? Como os envolveremos nas decisões e no planejamento? Com base em que concluiremos que nossas ações estão certas ou erradas? Como podemos cultivar uma organização onde nossos bisnetos teriam orgulho de trabalhar?" (ROBERTS, 1997, p. 217).

Na prática, o pensamento conectivo estimula as pessoas a enxergar e interpretar a realidade de forma sistêmica e, então, gerar soluções criativas, muitas vezes inesperadas, para problemas complexos. Enxergar o mundo sob uma perspectiva sistêmica requer o rompimento com o padrão linear de raciocínio. Significa identificar conjuntos de inter-relações, ao invés de cadeias lineares de causa-efeito, e processos de mudança, ao invés de acontecimentos isolados. As soluções criativas, por sua vez, são geradas a partir de novas percepções, explicações, invenções ou associações diferentes entre conceitos e idéias já existentes (ROGLIO, 2006).

Nessa perspectiva, o pensamento conectivo é fundamental compreender: (1) os diferentes elementos que compõem determinada situação ou problema; (2) as inter-relações entre esses elementos; (3) as influências recíprocas entre essas interrelações e o contexto social mais amplo. Essa percepção desperta a consciência sobre a relevância e urgência de estabelecer estratégias que promovam o desenvolvimento sustentável.

Messick e Bazerman (1996, p. 21) consideram que uma qualidade importante do processo decisório é a avaliação completa da extensão das conseqüências que as diretrizes organizacionais podem acarretar. Essa avaliação possibilita aos executivos tomarem decisões ao mesmo tempo éticas e estratégicas, o que "significa fazer a coisa certa e fazer a coisa inteligente".

Nessas decisões, continuam os autores, os executivos precisam (1) estimar detalhadamente as conseqüências para os stakeholders, pois as decisões socialmente responsáveis reconhecem que a organização é parte de uma ampla comunidade que tem interesse nas suas ações e (2) reconhecer que os seus efeitos não serão percebidos apenas no presente, mas também no futuro. Os executivos têm a responsabilidade de promover um desenvolvimento sustentável, isto é, gerenciar de forma que o ambiente social e físico mundial não seja destruído para as futuras gerações.

Em suas reflexões, Scharmer (2000, p. 7) afirma que um importante ponto cego na filosofia, ciência social e gerenciamento do século XX consiste em não enxergar a totalidade do processo de formação da realidade social:

$\mathrm{Na}$ experiência diária nós não enxergamos o que antecede a ação gerencial e a ação empresarial - os processos de pensamento que gradualmente conduzem ao desenvolvimento das idéias e iniciativas empresariais. Nós não enxergamos a totalidade do processo do vir-aser da ação social: nós não enxergamos o movimento descendente do pensamento e da consciência para a linguagem, o comportamento e a ação. Nós enxergamos oque fazemos. Nós também elaboramos teorias sobre como fazemos as coisas. Mas nós normalmente não temos consciência do referencial a partir do qual nós operamos quando agimos.

Uma causa desse ponto cego é a complexidade dinâmica dos sistemas, que explica as incoerências dos referenciais utilizados para a percepção e compreensão da realidade presente. Os princípios complexidade dinâmica dos sistemas, de acordo com Senge (1990), são: (1) a mesma situação tem efeitos dramaticamente diferentes no curto e longo prazos; (2) uma ação produz um conjunto de consequiências localmente e um conjunto muito diferente de resultados em outra parte do sistema; (3) intervenções óbvias produzem conseqüências não óbvias.

O primeiro princípio da complexidade dinâmica dos sistemas (a mesma situação tem efeitos dramaticamente diferentes no curto e longo prazos) está relacionado à dimensão temporal que o executivo usa para analisar as interrelações entre os elementos de uma determinada situação ou sistema.

Estudos indicam que grande parte das decisões dos gestores é baseada em análises de curto prazo e restritas aos contextos sobre os quais possuem controle mais imediato. Jackall (1988) afirma que os gestores parecem regularmente olhar para o curto prazo ao invés do longo prazo. Para ele, uma das razões está relacionada com a mentalidade de curto prazo dominante nos programas de desenvolvimento dos gestores, os seminários sobre gestão e a literatura especializada.

Mas a principal razão é decorrente da própria estrutura e velocidade do trabalho. A rotina gerencial é caracterizada por rápidos encontros e uma grande diversidade de assuntos. Neste ritmo, as coisas não chegam até os gestores de forma integrada, coerente, mas de forma fragmentada. Além disso, embora a maioria tenha consciência de que as questões menores de hoje podem se tornar rapidamente grandes crises amanhã, a pressão intensa por resultados anuais, mensais e diários, isto é, o progresso mensurável e atribuível ao esforço individual impede a reflexão sobre o futuro. A esse respeito, Jackall (1988, p. 84) afirma que "O coração do problema é este: os gestores pensam no curto prazo porque são avaliados, tanto pelos seus superiores como pelos seus pares, com base nos resultados de curto prazo".

Na concepção de Mintzberg (1989, p. 42), a ampliação da visão de curto prazo deve ser direcionada não apenas para o futuro, mas também para o passado. Segundo ele, embora estratégia seja uma palavra associada normalmente com o futuro, a sua ligação com o passado não é menos importante:

Os gestores podem ter que viver a estratégia no futuro, mas eles devem entendê-la com base no passado [...] as organizações precisam dar sentido ao passado se esperam administrar o futuro. Somente a partir da compreensão dos padrões que se formam no seu próprio comportamento elas podem conhecer as suas capacidades e o seu potencial. Desta forma, desenhar uma estratégia requer uma síntese natural do futuro, presente e passado.

O segundo princípio da complexidade dinâmica (uma ação produz um conjunto de conseqüências localmente e um conjunto muito diferente de resultados em outra parte do siste- 
ma) indica a necessidade do executivo mapear de forma abrangente e detalhada os elementos envolvidos e as interdependências que determinam a complexidade de uma situação ou sistema.

Diversos autores utilizam a metáfora da floresta para ilustrar esse princípio: os gestores precisam ser capazes de dar um passo para trás distante o suficiente dos detalhes para conseguir enxergar a floresta. Infelizmente, observa Senge (1990a, p. 128), ao fazer isto muitos deles enxergam apenas um monte de árvores e então escolhem uma ou duas favoritas e focam sua atenção e esforços para mudá-las. Ver a floresta, assim como as árvores, são fundamentais na prática reflexivas do executivo.

De fato, a arte do pensamento sistêmico consiste em enxergar através da complexidade para as estruturas subjacentes que estão gerando a mudança. O pensamento sistêmico não significa ignorar a complexidade. Antes, ele significa organizar a complexidade em uma história coerente que ilumina as causas dos problemas e como eles podem ser resolvidos de forma permanente.

O terceiro princípio da complexidade dinâmica (intervenções óbvias produzem conseqüências não óbvias) diz respeito às situações inesperadas. Os sistemas encontram-se em um processo contínuo de auto-transformação, assim como as relações entre os seus elementos. Deste modo, para compreendê-los é necessário contemplar a surpresa, o inesperado, a certeza provisória.

Drucker e Senge (2000) observam que o inesperado constitui um fator essencial para a gestão efetiva das organizações porque, assim como nos processos de criação, muitas das descobertas mais importantes nos processos de gestão não eram previstas. Com base no pensamento conectivo, o executivo reconhece as situações ou problemas inesperados e identifica diferentes possibilidades para resolvê-los.

A percepção sistêmica de mundo que os executivos desenvolvem com o pensamento conectivo fundamenta a análise e a compreensão das interações dinâmicas entre os sub-sistemas internos e externos que compõem o sistema organizacional nos processos decisórios. Essa percepção se manifesta, principalmente, na definição da estratégia organizacional.

De acordo com Mintzberg (1989), é preciso reconhecer que, na definição da estratégia é impossível prever todas as possibilidades, especialmente levando-se em conta a complexidade dos elementos envolvidos nessa definição. A imagem do futuro, em particular, é sensível às transformações nas relações interpessoais e processos organizacionais e às exigências dos diferentes ambientes externos com os quais a organização interage.

Esse autor afirma que a criação de uma estratégia integrada para atuar em um ambiente complexo e inter-relacionado demanda mais do que qualquer outro processo gerencial, o pensamento holístico, relacional. É necessário haver uma integração entre a estratégia deliberada e a estratégia emergente, que é desenvolvida gradualmente, ao longo das ações e experiências organizacionais, favorecendo a aprendizagem. Gerenciar a estratégia significa, assim, "combinar de forma criativa pensamento e ação, controle e aprendizagem, estabilidade e mudança" (MINTZBERG, 1989, p. 38).
Argyris e Schön (1996) trazem a idéia da formulação e concretização da estratégia organizacional como uma investigação contínua sobre o ambiente, de forma a torná-la flexível às suas constantes transformações. Com base nessa idéia, os autores estabelecem uma analogia com o processo de conversação reflexiva com uma situação: o ambiente complexo e de rápidas mudanças gera uma conversação reflexiva entre a organização e o seu ambiente. Nessa conversação, a organização se atualiza continuamente sobre a situação do ambiente, interage com essa situação por meio do design e da implementação de novas movimentações estratégicas e recebe supreendentes respostas (back talk) do ambiente, criando um ciclo de contínuo aperfeiçoamento e adaptação entre a estratégia organizacional e o seu ambiente.

\subsection{O pensamento conectivo como propulsor da consciên- cia sobre a relevância do desenvolvimento sustentável nos programas de educação executiva}

Diversos elementos concorrem para o desenvolvimento do pensamento conectivo nos programas de educação executiva: os princípios da aprendizagem de adultos; a atuação dos professores; as práticas pedagógicas; a aprendizagem coletiva; as estruturas curriculares (ROGLIO, 2006). Nesse trabalho, serão analisados com maior profundidade as práticas pedagógicas $\mathrm{e}$ as estruturas curriculares.

A análise das práticas pedagógicas utilizadas nos programas de educação executiva mostra que, considerando a impossibilidade de trabalhar somente com experiências primárias, os professores têm que adotar tecnologias que reproduzem situações gerenciais, tanto na esfera individual como coletiva. Jarvis et al. (1998, p. 58) observam que um fator relevante nessas experiências é a sua natureza:

uma grande quantidade de conhecimento sobre o mundo
não pode ser absorvida a partir de experiências primárias
[...] existem muitas situações nas quais nós temos que
aprender com experiências secundárias ou mediadas.
Nesses casos, nós temos que reconhecer que estamos
aprendendo a partir das experiências e interpretações
de outras pessoas. Essas devem ser avaliadas criticamente
antes de as aceitarmos. Mas, sem aprendermos a partir
de experiências secundárias, nosso conhecimento do
mundo seria seriamente limitado.

As possibilidades de reprodução de situações reais nos programas de educação executiva, investigadas neste artigo, são os micromundos e os estudos de caso, amplamente utilizados nesses programas. O centro dessas metodologias é uma situação simulada, desenhada para criar experiências pessoais para os aprendizes, que servem para desencadear o seu processo de reflexão, inquirição e compreensão do mundo real, seguindo os princípios da aprendizagem vivencial.

De acordo com Senge (1990), o termo micromundo foi criado por Seymour Papert, em 1970, para definir um ambiente de aprendizagem baseado em computador para crianças. Neste micromundo, as crianças podiam programar o ambiente, analisar as respostas e construir o seu próprio raciocínio sobre princípios matemáticos, solução de problemas e inter-relações entre matemática e lógica. Sendo assim, possibilitavam o exercício da 
criatividade e promoviam a aprendizagem com base na realização de experimentos em um mundo virtual, que dificilmente poderiam ser realizados no mundo real.

Gradualmente, o significado da palavra micromundo foi estendido para todos os tipos de simulação na qual as pessoas podem vivenciar situações, fazer experimentos, testar diferentes estratégias e construir um entendimento mais profundo do mundo real simulado pelo micromundo. Existem muitos micromundos projetados para simular situações organizacionais e eles têm sido amplamente utilizados nos programas de desenvolvimento gerencial, uma vez que representam um instrumento essencial para o aperfeiçoamento das capacidades decisórias, sem os riscos e custos do mundo real.

Na definição de Schön (1987), os micromundos ou mundos virtuais são ambientes de aprendizagem capazes de (1) reproduzir as características essenciais da prática a ser aprendida, possibilitando a realização de experiências sem os riscos envolvidos em uma situação real; (2) facilitar a adaptação do ritmo e foco do trabalho conforme as necessidades dos estudantes e do professor; (3) possibilitar a repetição das ações quando necessário. Em mundos virtuais, continua o autor, as limitações que poderiam inibir as experiências no mundo real são reduzidas: eles são contextos para experiências por meio dos quais os profissionais podem suspender ou controlar alguns dos impedimentos à reflexão-na-ação rigorosa. Todavia, adverte que "o mundo virtual é confiável somente se os resultados da experimentação puderem ser transferidos para o mundo real, e a validade dessa transferência depende da fidelidade com a qual o mundo virtual representa o mundo real" (SCHÖN, 1987, p. 77).

Os micromundos auxiliam na construção de protótipos que refletem a complexidade dinâmica dos sistemas e possibilitam a criação de diferentes possibilidades e combinações entre os elementos que compõem o processo decisório. Desta forma, estimulam os executivos a compreender a complexa rede de inter-relações entre as pessoas e os processos, dentro e fora do contexto organizacional, e dos seus impactos sobre os sistemas naturais e os sistemas sociais. Essa compreensão é um meio de despertar os executivos para a relevância e urgência de delinear estratégias que propiciem o desenvolvimento sustentável.

A visão sistêmica resultante do processo de aprendizagem baseado nos micromundos gera, de fato, uma mudança de mentalidade: "de nos enxergar como separados do mundo para nos enxergar conectados ao mundo, de enxergar os problemas como causados por alguém ou alguma coisa externa para enxergar como as nossas próprias ações criam os problemas que vivenciamos" (SENGE, 1990, p. 13).

Concomitante aos micromundos, a simulação de situações reais nos programas de educação executiva pode ser baseada em estudos de caso. O uso dos estudos de caso na educação gerencial é analisado por Christensen (1981), que considera as discussões sobre situações reais como uma ferramenta efetiva para aumentar a prática da reflexão, em particular quando os objetivos educacionais têm como foco:

- qualidades da mente - curiosidade, julgamento, sabedoria;

- qualidades da pessoa - caráter, sensibilidade, integridade, responsabilidade;
- habilidade para aplicar conceitos e conhecimentos específicos a situações específicas.

Esse autor acredita que o estudo de caso coloca os estudantes em um modo ativo de aprendizagem, os desafia a aceitar substancial responsabilidade pela sua própria educação e proporciona uma apreciação de primeira mão e experiência com a aplicação do conhecimento à prática.

Na visão de Schön (1987), nas escolas de administração a prática reflexiva pode ser exercitada por meio dos estudos de caso. Os professores hábeis na aplicação desse método conhecem diversas maneiras de utilizá-lo com esse propósito, que incluem desde a compreensão das interdependências entre os diferentes conteúdos abordados ao longo do programa até a conexão dos referenciais teóricos com a realidade prática dos estudantes. Na análise e apresentação desses casos, o diálogo entre os estudantes, as equipes e o professor são determinantes para o desenvolvimento do pensamento conectivo, que se manifesta de modo particular no mapeamento da situação exposta no caso e das relações entre os elementos envolvidos, na análise das diferentes possibilidades de interpretar a situação e no julgamento das conseqüências das decisões, que deve contemplar estratégias direcionadas à promoção do desenvolvimento sustentável.

Com relação ao design das estruturas curriculares dos programas de educação executiva, os principais fatores investigados neste artigo são a configuração interdisciplinar e os conteúdos abordados nas disciplinas. No seu formato atual, os currículos proporcionam a aprendizagem de pedaços de informação, relacionados com disciplinas particulares, o que dificulta e até mesmo impede o desenvolvimento do pensamento reflexivo e a ação do professor reflexivo.

Demo (2002a), Light e Cox (2001) e Schön (2000) sugerem a adoção de uma configuração interdisciplinar, construída a partir da integração entre tópicos que estimulam a reflexão sobre os padrões, as interações e as interdependências entre as diferentes áreas do conhecimento. De acordo com Demo (2002a), a partir de uma experiência prática podem ser explorados os diferentes conteúdos nela envolvidos e compreendidas as inter-relações entre eles, pois é desta forma que os fenômenos se apresentam no mundo real. A proposta desse autor extrapola as exigências normais de uma disciplina e o processo de aprendizagem de determinados conteúdos pode ultrapassar um trimestre, semestre ou até mesmo o período anual, sobretudo nos casos em que o enfoque da aprendizagem recai sobre a pesquisa. Por conseguinte, o processo de aprendizagem requer um período de tempo maior do que o ensino tradicional.

Light e Cox (2001, p. 93) fazem referência ao currículo em espiral que, numa perspectiva holística, possibilita aos estudantes:

revisitar temas e conceitos abordados anteriormente $\mathrm{e}$ analisá-los sob uma perspectiva diferente, desenvolvendo tanto a habilidade para lidar com múltiplas estruturas conceituais como para confrontar e/ ou integrá-las para construir novas perspectivas.

Bennis e O'Toole (2005, p. 104) constatam que o arriaulum dos programas de MBA como um todo "precisa ser infundido com questões e análises multidisciplinares, práticas e éticas que refletem os desafios complexos que os executivos enfrentam". 
O conceito de desenvolvimento sustentável terá maiores chances de ser compreendido e incorporado às estratégias organizacionais se for abordado em uma perspectiva interdisciplinar, pois é desta forma que ele se manifesta no mundo real.

Além de uma configuração interdisciplinar, diversos autores mencionam a necessidade de revisar os conteúdos abordados nos programas de educação executiva. Pfeffer e Fong (2002, p. 84) argumentam que diversas evidências sugerem que "o currículo ensinado nas escolas de administração possuem pouca relação com o que é importante para o sucesso nos negócios". Grey (2004), por exemplo, critica o foco quase exclusivo da educação em administração nos interesses das organizações e dos gestores ao invés dos interesses dos stakeholders na organização e na sociedade. De acordo com esse autor, "valores e contextos deveriam ser analisados e discutidos nas salas de aula como parte integral dos programas" (GREY, 2004, p. 180).

Adler sintetiza as discussões realizadas em agosto de 2002 pelos membros do Critical Management Studies Interest Group of the Academy of Management. Instigadas pelos recentes escândalos corporativos nos Estados Unidos, as discussões abordaram as relações entre as escolas de administração - que, em última instância, são responsáveis pela formação dos executivos - e as origens desses escândalos. Algumas das idéias discutidas sobre o currículo das escolas de administração foram:

- Além de constituir uma disciplina específica no currículo, a ética deve ser parte integrante de todas as demais disciplinas;

- A atenção para as questões éticas deve ter como foco não apenas a probidade individual, mas também o modo como as estruturas sociais incentivam ou desencorajam o comportamento ético e não-ético;

- Devem ser instituídas disciplinas obrigatórias sobre a história das organizações, do governo e da sociedade, que sensibilizem os estudantes para o conjunto de visões e questões envolvidas, para as suas mudanças ao longo do tempo e para as variações entre os diferentes países. Essas disciplinas podem auxiliar os estudantes a adquirir a capacidade para o pensamento conectivo que o seu papel enquanto gestores e cidadãos.

Somados às questões éticas envolvidas nos processos decisórios e suas conseqüências, o desenvolvimento do pensamento conectivo pode ser estimulado por assuntos que exploram idéias relacionadas com a: (1) compreensão da conectividade entre os sistemas naturais e sociais; (2) identificação de alternativas para o desenvolvimento sustentável; (3) análise da complexidade dinâmica dos sistemas e os seus impactos sobre a existência do ser humano, das organizações e das sociedades; (4) discussão da visão do mercado como espaço central da vida humana associada e compreensão dos outros espaços; (5) definição de estratégias socialmente responsáveis e identificação de alternativas para a vida comunitária.

Por isso, considera-se importante que os seguintes conteúdos sejam explorados com profundidade nos programas de educação executiva não apenas enquanto o núcleo de disciplinas específicas, mas inseridos nas construções de conhecimento das diversas disciplinas do currículo: pensamento sistêmico; de- senvolvimento sustentável; ética e cidadania. Na elaboração desses conteúdos, é preciso ter como referência a idéia de que é necessário restabelecer a conexão entre a ciência e a filosofia para que se possa compreender a realidade complexa e enfrentar de forma eficaz os desafios apresentados por ela. Sem essa reconexão, continuar-se-á preso ao pensamento simplificador e a uma educação característica da concepção mecanicista.

\section{CONSIDERAÇÕES FINAIS E RECOMENDAÇÕES}

Neste ensaio foram apresentadas possibilidades para o desenvolvimento do pensamento conectivo em Programas de Educação Executiva como uma forma de estimular a consciência dos executivos sobre a relevância e a urgência de estabelecer estratégias que contemplem o desenvolvimento sustentável. Uma sociedade avançada em equilíbrio com o seu ambiente requer uma compreensão profunda da natureza dos sistemas complexos e é nesse sentido que o pensamento conectivo constitui uma forma de mobilizar os executivos para a construção de uma sociedade sustentável.

O foco no público executivo deve-se, principalmente, à influência das organizações sobre a vida de quase todas as outras espécies no planeta. Historicamente, adverte De Geus (1998), nenhum indivíduo, tribo ou mesmo nação poderia alterar o clima global, destruir milhares de espécies ou alterar o balanço químico da atmosfera. Isso é exatamente o que está acontecendo hoje, na medida em que as ações individuais estão sendo mediadas e ampliadas ao longo da rede crescente de organizações globais.

O papel da educação na participação responsável dos indivíduos e das organizações no desenvolvimento da sociedade é hoje discutido de forma ampla nos diversos níveis do sistema educacional e áreas do conhecimento. $\mathrm{O}$ desenvolvimento do pensamento conectivo em Programas de Educação Executiva analisado neste artigo representa um caminho para superar o desafio de transformar as escolas mecanicistas, criticadas por sua visão reducionista e em descompasso com o ritmo das mudanças contemporâneas, em escolas que se caracterizam como organizações em aprendizagem, capazes de desenvolver profissionais com as competências requeridas pelo atual ambiente de complexidade.

Neste artigo, os elementos analisados nos Programas de Educação Executiva - as práticas pedagógicas e a configuração interdisciplinar do currículo - são importantes para que o pensamento conectivo seja incorporado aos processos decisórios dos executivos. Os principais reflexos desse pensamento na definição das estratégias organizacionais são a concepção da organização como uma rede viva complexa e a compreensão dos impactos das decisões executivas para o desenvolvimento sustentável da sociedade. No entanto, esses elementos precisam ser ampliados, investigados de modo empírico, examinados e debatidos como uma alternativa aos desafios e oportunidades da educação executiva.

Espera-se que as idéias levantadas neste ensaio sejam propulsoras de debates em torno do tema, ampliando os estudos sobre o papel da educação executiva, que estão sendo instigados pela Academy of Management Learning and Education e, no Brasil, pela Associação Nacional de Pós-Graduação e Pesquisa em Administração (ANPAD). 
Existe um campo fértil para a realização de estudos correlatos ao tema abordado neste artigo. Com relação a variações no foco da investigação, considera-se relevante o desenvolvimento de pesquisas que tenham como objeto:

- O design e a implantação de outras práticas de aprendizagem - como as comunidades de prática - capazes de estimular o desenvolvimento do pensamento conectivo no contexto organizacional;

- O acompanhamento do desenvolvimento do pensamento conectivo ao longo de um Programa de Educação Executiva, de forma a identificar sua influência sobre a consciência dos executivos sobre a relevância e a urgência do desenvolvimento sustentável;

- Estratégias de transferência da consciência sobre o desenvolvimento sustentável, estimulada em programas de educação executiva, para os processos decisórios do executivo;

- Diferenças no modo como os executivos interpretam e aplicam o conceito de desenvolvimento sustentável na definição das estratégias organizacionais.

\section{REFERÊNCIAS}

ADLER, P. S. Corporate scandals: it's time for reflection in business schools. A cademy of Management Exeautive, vol. 16, n. 3, p. 148-149, 2002.

ARGYRIS, C. The executive mind and double-loop learning. Organizational Dynamics, v. 11, n. 2, p. 5 (18 p), Autumm 1982.

ARG YRIS, C.; SCHÖN, D. Organizational Learning II: theory, method, and practice. New York: Addison Wesley, 1996.

AXELROD, R.; COHEN, M. D. Harnessing complex ity organizational implications of a scientific frontier. New York: The Free Press, 2000.

BENNIS, W. G.; O'TOOLE, J. How business schools lost their way. Harvard Business Review, v. 83, n. 5, p. 96-104, May 2005.

CHRISTENSEN, R. Teaching and the case method. Boston: Harvard Business School, 1981.

DAVEL, E.; VERGARA, S.; GHADIRI, S.; FISCHER, T. Revitalizando a relação ensino-aprendizagem em administração por meio de recursos estéticos. In: ENCONTRO NACIONAL DA ASSOCIAÇÃO NACIONAL DOS PROGRAMAS DE PÓSGRADUAÇÃO EM ADMINISTRAÇÃO (ENANPAD). Anais... Curitiba: ANPAD, 2004. CD-ROM.

DE GEUS, A. P. A empresa viva: como as organizações podem aprender a prosperar e se perpetuar. Rio de Janeiro: Campus, 1998.

DELORS, J. (org.). Educação: um tesouro a descobrir. 4.ed. São Paulo: Cortez; Brasília: MEC: UNESCO, 2000.

DEMO, P. Política científica e educacional na Universidade. Porto alegre: Revista Educação, ano XXV, n. 47, p. 07-21, junho 2002.

Educar pela pesquisa. 5. ed. Campinas: Autores Associados, 2002a.

DRUCKER, P.; SENGE, P. M. Meeting of the minds. A crass the Board. New York: v. 37, n. 10, p. 16 (6 p.), nov/ dez 2000.

EHRENFELD, J.R. Searching for sustainability: no quick fix. Reflections, v. 5, n. 8, 2004.

FULLAN, M.; HARGREAVES, A. A escola como organização aprendente: buscando uma educação de qualidade. 2. ed. Porto Alegre: Artes Médicas Sul, 2000.
GHOSHAL, S. Bad management theories are destroying good management practices. Academy of Management Learning \& Education, v. 4, n. 1, p. 75-91, 2005.

GOSLING, J.; MINTZBERG, H. The five minds of a manager. Harvard Business Review. Boston: v. 81, n. 11, p. 54-64, Nov 2003.

GREY, C. Reinventing business schools: the contribution of critical management education. Academy of Management Learning and Education, v. 3, n. 2, p. 178-186, 2004.

HOCK, D. Nascimento da era caórdica. São Paulo: Cultrix, 1999.

JACKALL, R. Moral Mazes: the world of corporate managers. New York: Oxford University Press, 1988.

JARVIS, P.; HOLFORD, J.; GRIFFIN, C. The theory and pradice of learning. London: Kogan Page, 1998.

KOLB, D. Experiential L earning. experience as the source of learning and development. Englewood Cliffs: Prentice-Hall, 1984.

LIGHT, G.; COX, R. Learning and teaching in higher education: the reflective professional. London: Sage Publications, 2001.

MESSICK, D. M.; BAZERMAN, M. H. Ethical leadership and the psychology of decision making. Sloan Management Review, v. 37, n. 2. p. 9-22, Winter 1996.

MINTZBERG, H. Mintzbergon management: inside our strange world of organizations. New Work: The Free Press, 1989.

MORGAN, G. Imagens da organização. Ed. Executiva. São Paulo: Atlas, 2000.

MORIN, E.; LE MOIGNE, J. A inteligência da complexidade. 2. ed. São Paulo: Peirópolis, 2000.

MORIN, E. Os sete saberes necessários à educação do futuro. 6. ed. São Paulo: Cortez; Brasília, DF: UNESCO, 2002.

OSTERMAN, K. F.; KOTTKAMP, R. B. Reflective practice for educators: professional development to improve student learning. 2. ed. Thousand Oaks: Cowin Press, 2004.

PFEFFER, J; FONG, C. T. The end of business schools? Less success than meets the eye. A cademy of Management Learning and Education, v. 1, p. 78-95, 2002.

REYNOLDS, M.; VINCE, R. Critical Management education and action-based learning: synergies and contradictions. A cademy of Management Learning and Education, v. 3, n. 4, p. 442-456, 2004.

ROBERTS, C. Maestria intrapessoal. In: SENGE, P.; ROSS, R.; SMITH, B. et al. A quinta disciplina caderno de campo: estratégias e ferramentas para construir uma organização que aprende. Rio de Janeiro: Qualitymark Ed., 1997.

ROGLIO, K. D. O ex eautivo reflexivo: arquiteto e facilitador de novas configurações organizacionais. Florianópolis, 2006. Tese (Doutorado em Engenharia de Produção) - Programa de Pós Graduação em Engenharia de Produção, Universidade Federal de Santa Catarina.

SCHARMER, C. O. Illuminating the blind spot: leadership in the context of emerging worlds. Boston, 1999-2000. Disponível no site www.dialogonleadership.org.

SCHÖN, D. A. Educando o profissional reflexivo: um novo design para o ensino e a aprendizagem. Porto Alegre: Artes Médicas Sul, 2000.

SCHÖN, D. A. Educatingthereflectivepractitioner. San Francisco: Jossey Bass, 1987.

The reflective practitioner: how professionals think in action. New York: Basic Books, 1983.

SENGE, P. M. Creating desired futures in a global economy. Boston: Reflections, v. 5, n. 1, p. 1-12, 2003.

The fifht discipline: the art and practice of the learning organization. New York: Doubleday, 1990a. 
. A quinta disciplina. São Paulo: Best Seller, 1990.

SENGE, P. M.; LAUR, J. SCHLEY, S.; SMITH, B. L earning for sustainability. Cambridge: The Society for Organizational Learning, 2006.

SENGE, P. M.; SCHARMER, C. O.; JAWORSKI, J;; FLOWERS, B. S. Presence human purpose and the field of the future. Cambridge: The Society for Organizational Learning, 2004.

SENGE, P. M.; CAMBRON-MCCABE, N.; LUCAS, T.; SMITH, B.; DUTTON, J.; KLEINER, A. Schools that learn. New York: Doubleday, 2000.

SMITH, G. F. Beyond critical thinking and decision making: teaching business students how to think. Journal of Management Education. Thousand Oaks, v. 27, n.1, p. 24 (28 p), Feb 2003.

SMITH, P. Action learning and reflective practice in project environments that are related to leadership development. Management Learning. Thousand Oaks, v. 32, n. 1, p. 31-48, 2001.

SMYRE, R. "It" is more than "either/ or": a need for connective thinking. Futures Research Quarterly, v. 20, n. 2, p 68-79, Summer 2004.

SOUTHWORTH, G. How primary schools learn. Research Papers in Education, v. 15, n. 3, p. 275-291, 2000.

STACEY, R. D. Complex ity and creativity in organizations. San Francisco: Berret-Koehler Publishers, 1996.

WHEATLEY, M. Liderança e a nova ciência. 9.ed. São Paulo: Cultrix, 1999. 
